\title{
Observer Based Identification of Unbalanced Magnetic Pull in Asynchronous Motors
}

\author{
K. O. Boynov*, E. A. Lomonova ${ }^{\S}$ \\ *Protonic Holland BV \\ Factorij 36, 1689 AL, Zwaag, The Netherlands \\ Tel.: +31/(0)-229-212928, Fax: +31/(0)-229-210930 \\ E-Mail: konstantin.boynov@protonic.nl URL: http://www.protonic.nl/ \\ $\S$ Department of Electrical Engineering \\ Eindhoven University of Technology \\ P.O. Box 513, Eindhoven, The Netherlands \\ Tel.: +31/(0)-40-2473573, Fax: +31/(0)-40-2434364 \\ Email: e.lomonova@tue.nl, URL: http://w3.ele.tue.nl/nl/epe/
}

\begin{abstract}
This paper presents an iterative approach to identification of sources and characteristics of rotor and airgap eccentricity and, consequently, unbalanced magnetic pull (UMP) in asynchronous motors. The presented method is based on the number of mathematical modeling techniques, namely: finite elements method (FEM), Lagrangian dynamics and optimal estimation in combination with experimental measurements.
\end{abstract}

\section{INTRODUCTION}

Three main types of noise are encountered in electrical motors: electromagnetic, mechanical, aerodynamical [1]-[3]. Electromagnetic noise is the general component of the acoustic noise and vibrations, which results as the action of the magnetic (excited) forces in the airgap. Additional magnetic noise from AC motors driven by PWM inverters is caused by the high-frequency harmonics contained in the output waveforms [4], [5].

As soon as the airgap magnetic flux density is not purely sinusoidal it comprises the fundamental, together with an infinite series of harmonics. In general, these harmonics are of the primer interest for the noise analysis. They are caused by the following factors:

- variations in the airgap length caused by the presence of eccentricity and slots;

- non-sinusoidal stator and rotor windings;

- saturation;

- harmonics originating from the PWM-inverter supply.

This paper is primary focused on the diagnostic of the motor vibrations caused by eccentricity of the airgap length and, consequently, unbalanced magnetic pull in cage induction motors.

There are number of developed and published methods for diagnostics of the motor vibrations [6], [7]. The most of the techniques are primarily dedicated to vibration diagnostics of large machines and using direct measurements of the airgap length, e.g. with the proximity sensors. However, in the small motors of the range of hundreds watts, the placement of the sensor would be impossible without violating of the mechanical and magnetic structure of the machine. Thus, the proposed method employs stator vibrations measurements with the further application of the model-based identification techniques (Fig. 1).

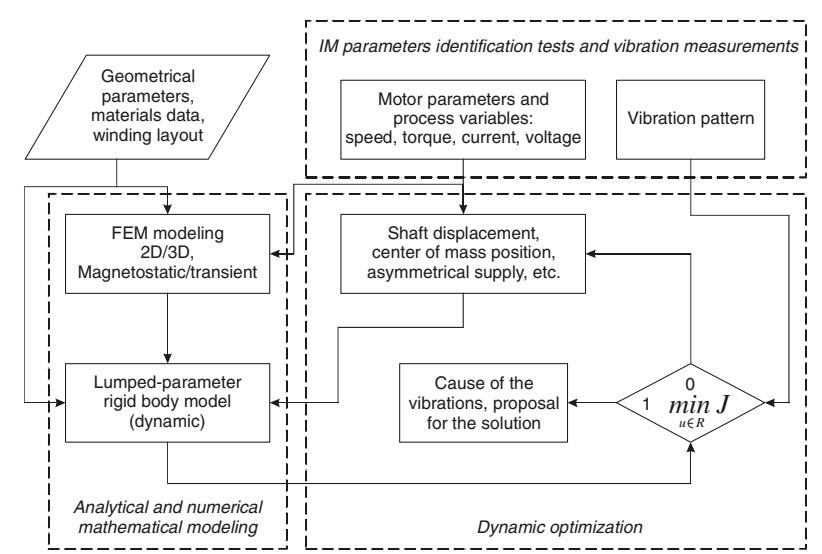

Figure 1. Iterative analysis flow-chart for identification of induction motors vibrations.

\section{ROTOR AND AIRGAP ECCENTRICITY AND MAGNETIC FORCES}

In rotating electrical machines, eccentricity is classified taking into account mechanical and electromagnetic phenomena. The mechanical issue mainly concerns the relative location of the rotation axis of the rotor and its center of mass, while magnetic nature is put forward in case of variable airgap length.

In the present work, eccentricity is characterized by four vectors of displacement (Fig. 2):

- $\varepsilon_{\mathrm{cr}}-$ center of rotation displacement, $[\mathrm{m}]$;

- $\varepsilon_{\mathrm{gc}}$ - geometrical center displacement, $[\mathrm{m}]$;

- $\varepsilon_{\delta}=\varepsilon_{\mathrm{cr}}+\varepsilon_{\mathrm{gc}}-$ airgap displacement, [m];

- $\varepsilon_{\mathrm{cm}}$ - center of mass displacement, [m]. 


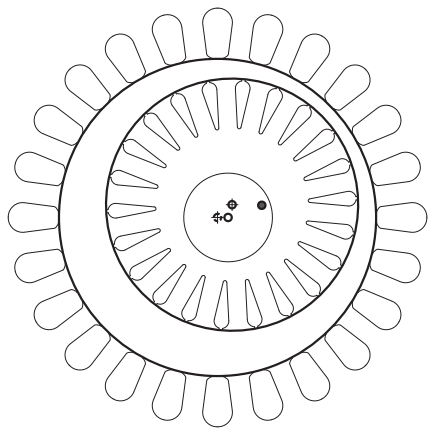

(a)

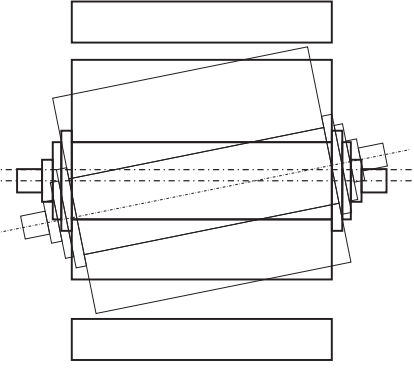

(b)

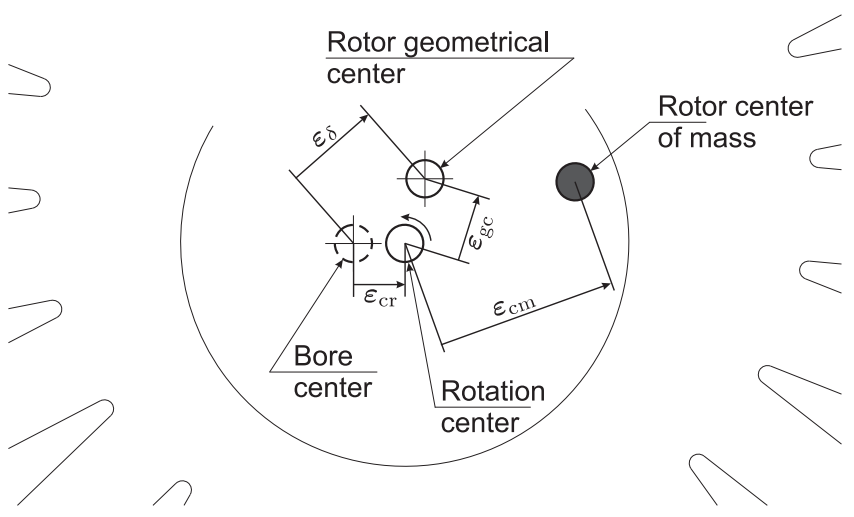

(c)

Figure 2. Airgap and rotor eccentricity: (a) Radial eccentricity, (b) Axialvarying eccentricity, (c) Zoomed view of the center of (a).

The listed displacements will define the UMP and vibration characteristics of the motor.

In case of symmetrical airgap, the attraction reluctance force between the stator and the rotor are equally distributed along the surfaces of the stator and the rotor magnetic cores. However, if the rotor is radially displaced with respect to the stator, the attraction force becomes unbalanced.

The electromagnetic force acting between the rotor and the stator can be computed by integrating the Maxwell stress tensor, $\sigma$, over the bore and the rotor surfaces.

$$
\begin{gathered}
\boldsymbol{F}=\oint_{\mathrm{S}} \boldsymbol{\sigma} d \boldsymbol{S} \\
\sigma_{\mathrm{ij}}=\frac{1}{\mu_{0}} B_{\mathrm{i}} B_{\mathrm{j}}-\frac{1}{2 \mu_{0}} B^{2} \delta_{\mathrm{ij}}
\end{gathered}
$$

where

$\boldsymbol{\sigma}$ - Maxwell stress tensor, $\left[\mathrm{N} / \mathrm{m}^{2}\right]$,

$S$ - integration surface, $\left[\mathrm{m}^{2}\right]$,

$B$ - magnetic flux density, $[\mathrm{T}]$,

$\mu_{0}=4 \pi \cdot 10^{-7}$ permeability of vacuum, $[\mathrm{H} / \mathrm{m}]$,

$\delta_{\mathrm{ij}}$ - Kronecker's delta.

The magnetic field and, consequently, the force are primarily defined by two factors, i.e. the absolute value of magnetomotive force (MMF) and the relative position of the stator and the rotor cores surfaces. Due to variable MMF, the attraction force will oscillate with the frequency twice of that of the supply frequency. This phenomenon is commonly referred to as "double line frequency oscillations". Furthermore, in case of constant airgap displacement, or so-called "static" eccentricity, $\left(\varepsilon_{\delta}=\right.$ const, $\left.\varepsilon_{\mathrm{gc}}=0\right)$, vibrations will not depend on the rotor position. On the contrary, in case of "dynamic" eccentricity $\left(\varepsilon_{\mathrm{gc}} \neq 0\right)$ oscillations will be modulated by the mechanical angular frequency.

For the particular motor geometry and its operating regime, the magnetic field of the induction motor has been solved using multi-slice, finite element analysis, where such effects like slotting, skewing, damping currents and slot saturation (Fig. 3), which lead to highly non-linear behavior, are precisely treated. The obtained solutions of electromagnetic force are presented in Figs. 5 and 4. Figure 5 shows the attraction force at 75 per cent of the airgap displacement and the rated magnetizing current, and Fig. 4 demonstrates the dependence of the force on the displacement. Obtained results of the FEM modeling are further used in the characterization of eccentricity of the airgap, together with the results of the mechanical system analysis and measurements.

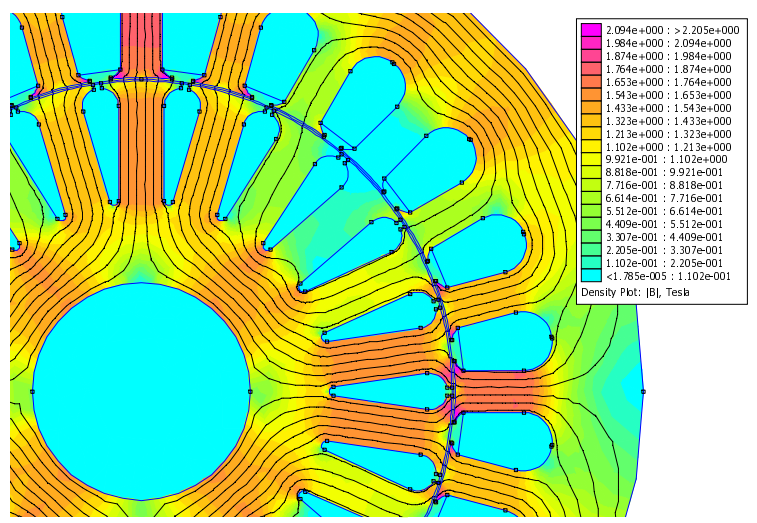

Figure 3. Magnetic flux density obtained from FEM.

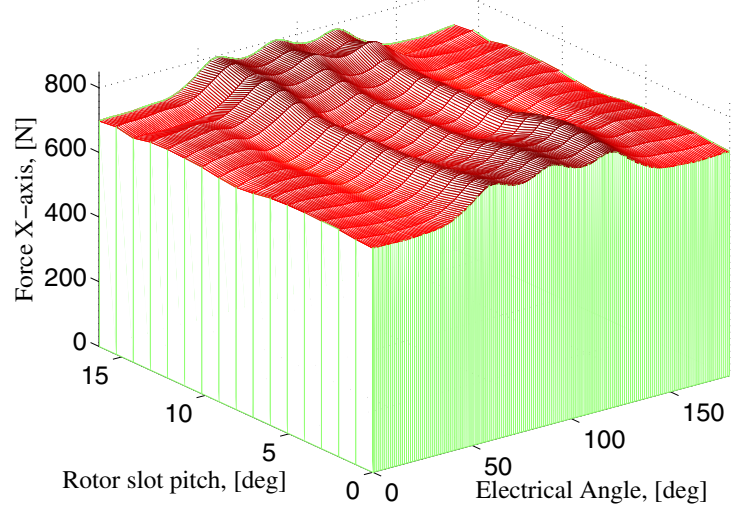

Figure 4. Reluctance force along X-axis obtained from FEM. 


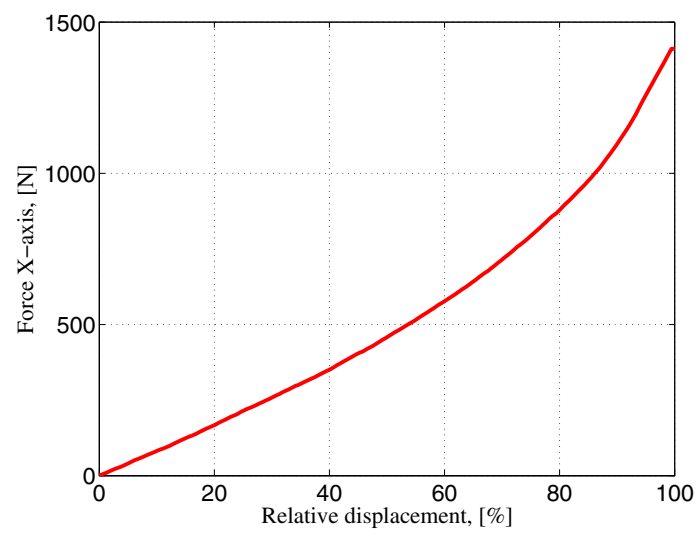

Figure 5. Reluctance force vs. gap displacement $\varepsilon_{\delta}$.

\section{MECHANICAL MODEL}

The mathematical model of the mechanical system is the key component of the observer system. The original equations of motion are obtained by applying the Euler-Lagrange method [8]-[11] onto 8-DOF mechanical structure of rigid bodies (the stator and the rotor):

$$
\begin{gathered}
\frac{d}{d t}\left(\frac{\partial L}{\partial \dot{q}}(q, \dot{q})\right)-\frac{\partial L}{\partial q}(q, \dot{q})=F \\
L(q, \dot{q})=T(q, \dot{q})-V(q)
\end{gathered}
$$

where

$q$ - generalized coordinates,

$L$ - Lagrangian function, $[\mathrm{J}]$,

$F$ - external forces (torques), $[\mathrm{N}(\mathrm{Nm})]$,

$T$ - kinetic energy, $[\mathrm{J}]$,

$V$ - potential energy, $[\mathrm{J}]$.

The equivalent model for the investigated mechanical system (Fig. 6) is derived applying the following simplifications:

- The bending of the shaft, deformation of the stator and their axial motion are neglected;

- The cross-coupling between $x$ and $y$ - axis stiffness and damping of bearings are neglected;

- The rotation of the rotor is assumed steady-state, thus the angular speed is not included in states;

- Angular displacement $\left(\theta_{\mathrm{x}(\mathrm{y}) \mathrm{s}(\mathrm{r})}\right)$ of the stator and the rotor is assumed very small with respect to the core length, $l_{\mathrm{c}}$, thus $\cos \left(\theta_{(\cdot)}\right) \cong 1, \sin \left(\theta_{(\cdot)}\right) \cong \theta_{(\cdot)}$ and $\sin ^{2}\left(\theta_{(\cdot)}\right) \ll$ $\sin \left(\theta_{(\cdot)}\right)$ and $\theta_{(\cdot)}=\left(x(y)_{1 \mathrm{~s}(\mathrm{r})}-x(y)_{2 \mathrm{~s}(\mathrm{r})}\right) /\left(l_{\mathrm{c}} / 2\right)$.

The potential energy of the system is the following:

$$
\begin{aligned}
& V=\frac{k_{\mathrm{b}}}{2}\left(\Delta x_{1 \mathrm{sr}}^{2}+\Delta x_{2 \mathrm{sr}}^{2}+\Delta y_{1 \mathrm{sr}}^{2}+\Delta y_{2 \mathrm{sr}}^{2}\right)+ \\
& +\frac{k_{\mathrm{s}}}{2}\left(x_{1 \mathrm{~s}}^{2}+x_{2 \mathrm{~s}}^{2}+y_{1 \mathrm{~s}}^{2}+y_{2 \mathrm{~s}}^{2}\right)
\end{aligned}
$$

where $k_{\mathrm{b}}$ - bearing (housing) stiffness, $[\mathrm{N} / \mathrm{m}]$,

$k_{\mathrm{S}}$ - suspension stiffness, $[\mathrm{N} / \mathrm{m}]$,

$\Delta(x, y)_{(1,2) \mathrm{sr}}=(x, y)_{(1,2) \mathrm{s}}-(x, y)_{(1,2) \mathrm{r}}-$ stator and rotor relative displacement, $[\mathrm{m}]$.

The kinetic energy, $T$, of the system is composed from rotational, $T_{\text {rot }}$, and translational, $T_{\mathrm{tr}}$, components:

$$
\begin{gathered}
T=T_{\mathrm{rot}}+T_{\mathrm{tr}}, \\
T_{\mathrm{rot}}=\frac{1}{2}\left[I_{\mathrm{xy}, \mathrm{r}}\left(\dot{\theta}_{\mathrm{xr}}^{2}+\dot{\theta}_{\mathrm{yr}}^{2}\right)+I_{\mathrm{xy}, \mathrm{s}}\left(\dot{\theta}_{\mathrm{xs}}^{2}+\dot{\theta}_{\mathrm{ys}}^{2}\right)+\right. \\
\left.+I_{\mathrm{z}, \mathrm{r}}\left(\omega^{2}-2 \omega \dot{\theta}_{\mathrm{yr}} \theta_{\mathrm{xr}}\right)\right], \\
T_{\mathrm{tr}}=\frac{1}{2}\left[m_{\mathrm{s}}\left(\dot{x}_{\mathrm{cm}, \mathrm{s}}^{2}+\dot{y}_{\mathrm{cm}, \mathrm{s}}^{2}\right)+m_{\mathrm{r}}\left(\dot{x}_{\mathrm{cm}, \mathrm{r}}^{2}+\dot{y}_{\mathrm{cm}, \mathrm{r}}^{2}\right)\right],
\end{gathered}
$$

where

$w$ - rotor angular velocity, $[\mathrm{rad} / \mathrm{s}]$,

$(x, y)_{\mathrm{cm}}$, - coordinates of the stator (rotor) center of mass, $[\mathrm{m}]$.

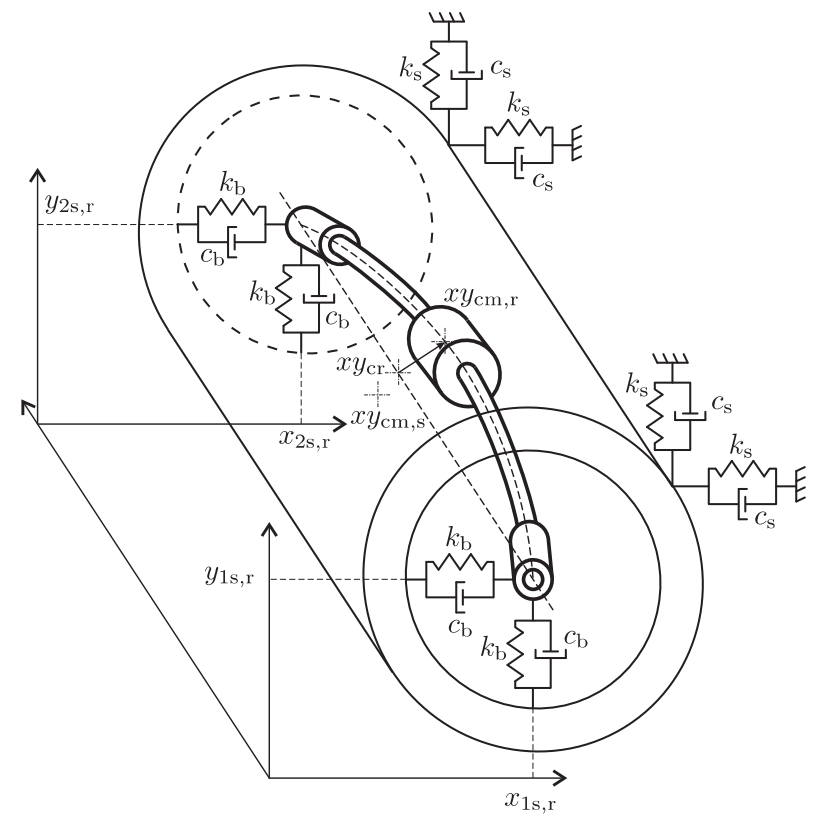

Figure 6. Equivalent mechanical model.

The system of equations of motion is expressed in the following form:

$$
[m, I][\ddot{q}]+[c,(I \omega)][\dot{q}]+[k][q]=[F]
$$

where

$[m, I]-$ mass and inertia matrix,

$[c,(I \omega)]$ - damping and gyroscopic matrix,

$[k]$ - stiffness matrix. 


\section{EXPERIMENTAL MEASUREMENTS}

The experimental measurements have been performed on the industrial induction motor (Table I), modified in such a way, that it allows radial displacement of the rotor with respect to the stator. Two 3D accelerometers have been fixed on the stator housing, as shown in Fig. 7.

Table I

PRINCIPAL MOTOR DESIGN PARAMETERS OF THE 4-POLE IM.

\begin{tabular}{|c|c|}
\hline Rated power, $P_{\mathrm{d}},[\mathrm{W}]$ & 750 \\
\hline Rotor diameter, $D_{\mathrm{r}},[\mathrm{mm}]$ & 70 \\
\hline Stator outside diameter, $D_{\mathrm{s}},[\mathrm{mm}]$ & 150 \\
\hline Shaft diameter, $D_{\mathrm{sh}},[\mathrm{mm}]$ & 26 \\
\hline Airgap length, $\delta,[\mathrm{mm}]$ & 0.5 \\
\hline Number of stator slots, $Z_{\mathrm{s}},[-]$ & 24 \\
\hline Number of rotor slots, $Z_{\mathrm{r}},[-]$ & 22 \\
\hline Skew length, $k_{\mathrm{skew}},[\mathrm{mm}]$ & 10 \\
\hline Core length, $l_{\delta},[\mathrm{mm}]$ & 70 \\
\hline Rotor mass, $m_{\mathrm{r}},[\mathrm{kg}]$ & 3.5 \\
\hline Stator mass, $m_{\mathrm{s}},[\mathrm{kg}]$ & 6.25 \\
\hline Rotor inertia $(x, y-$ axis $), I_{\mathrm{xy}, \mathrm{r}},\left[\mathrm{kgm}^{2}\right]$ & 0.0021 \\
\hline Rotor inertia $(z-$ axis $), I_{\mathrm{z}, \mathrm{r}},\left[\mathrm{kgm}^{2}\right]$ & 0.0018 \\
\hline Stator inertia $(x, y-$ axis $), I_{\mathrm{xy}, \mathrm{s}},\left[\mathrm{kgm}^{2}\right]$ & 0.0109 \\
\hline
\end{tabular}

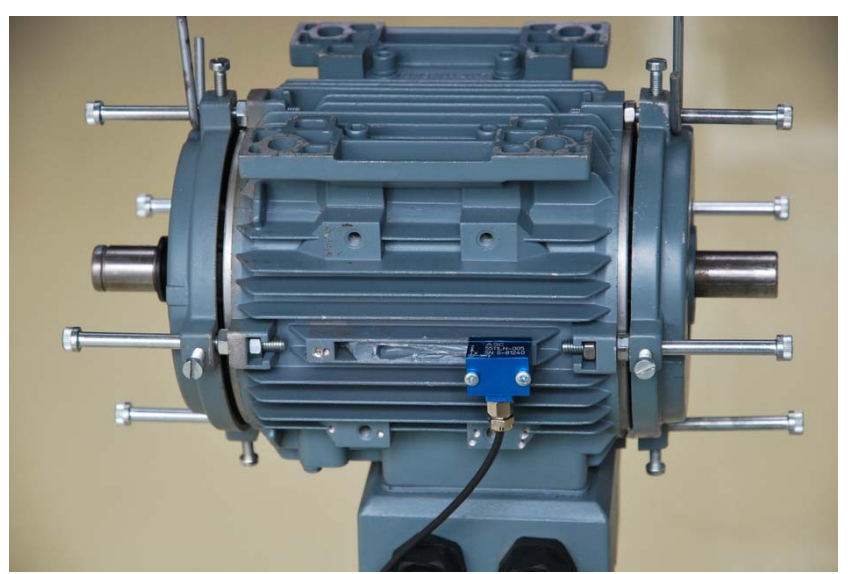

Figure 7. Motor under the test.

As it was mentioned in the first section, there are several sources of vibration in the IM with the mechanical or electromagnetic nature. Therefore, the measurements have been carried out in a way to minimize the effect of different sources of vibration on each other.

As it can be seen in the Fig. 4, in case of three-phase supply, the electromagnetic force would have a significant DC component, which is about $85 \%$ of the total force. Thus, in case of static eccentricity, the only effect of AC component will be measurable, which is rather low. As the result, the measurements on the rotating machine under the regular three-phase supply can be quite inaccurate due to the limited sensitivity of the accelerometers. Consequently, it was proposed to perform the measurements of static eccentricity under the single-phase supply, with all motor phases connected in series. Such a configuration creates symmetric, non-rotating magneto-motive force (MMF) and, consequently, produces pulsating magnetic field. As the result, the AC component of the electromagnetic force has full amplitude, and resulted motion can be more accurate detected by the accelerometers.

Five tests on static airgap eccentricity have been carried out, corresponding to the rotor displacement in different directions:

- no displacement;

- linear displacement along $x$-axis;

- linear displacement along $y$-axis;

- combined linear displacement along $x$ - and $y$ - axis;

- angular displacement around $y$-axis.

The acceleration measurements results together with estimated force for five cases of airgap eccentricity and artificially created rotor eccentricity (the last plot) are presented in Figs. $9-14$.

\section{OPtimAL ESTIMATOR}

Finally, with the use of the optimal estimation [12], [13], combining measurements performed on the motor (parameters, process variables (stator current, $I_{\mathrm{s}}$, and frequency, $f_{\mathrm{s}}$ ) and vibrations) with numerical and analytical modeling, the identification of the UMP and rotor eccentricity are performed. The general scheme of the estimator is presented in Fig. 8.

For the simplification of the observer design, the current work deals with the linear quadratic (LQ) problem. The LQ stands for linear systems with quadratic performance criteria. The optimal observer design methods convert control/observer system design problems to an optimization problem with timedomain performance criteria. With the LQ approach, the feedback observer coefficients are designed so that the following cost functional $J_{\mathrm{c}}$ is minimized under the "constraint" of the system dynamics $\dot{x}$ :

$$
\begin{aligned}
& \min _{\mathrm{u}(\mathrm{t})} \quad J_{\mathrm{c}}=\frac{1}{2} \int_{0}^{\infty}\left(y(t)^{\mathrm{T}} Q y(t)+u(t)^{\mathrm{T}} R u(t)\right) d t \\
& \text { subject to } \dot{x}=f(x, u), x\left(t_{0}\right)=x_{0}
\end{aligned}
$$

where

$$
\begin{aligned}
& x(t)=\left[\begin{array}{c}
x_{\mathrm{s}, \mathrm{r}} \\
\dot{x}_{\mathrm{s}, \mathrm{r}} \\
y_{\mathrm{s}, \mathrm{r}} \\
\dot{y}_{\mathrm{s}, \mathrm{r}} \\
\theta_{\mathrm{x}, \mathrm{s}, \mathrm{r}} \\
\dot{\theta}_{\mathrm{x}, \mathrm{s}, \mathrm{r}} \\
\theta_{\mathrm{y}, \mathrm{s}, \mathrm{r}} \\
\dot{\theta}_{\mathrm{y}, \mathrm{s}, \mathrm{r}}
\end{array}\right], y(t)=\left[\begin{array}{c}
x_{\mathrm{s}, \mathrm{r}} \\
\dot{x}_{\mathrm{s}, \mathrm{r}} \\
y_{\mathrm{s}, \mathrm{r}} \\
\dot{y}_{\mathrm{s}, \mathrm{r}} \\
\theta_{\mathrm{x}, \mathrm{s}, \mathrm{r}} \\
\dot{\theta}_{\mathrm{x}, \mathrm{s}, \mathrm{r}} \\
\theta_{\mathrm{y}, \mathrm{s}, \mathrm{r}} \\
\dot{\theta}_{\mathrm{y}, \mathrm{s}, \mathrm{r}}
\end{array}\right] \text { and } \\
& u(t)=\left[\begin{array}{c}
F_{\mathrm{x}, \mathrm{s}, \mathrm{r}} \\
F_{\mathrm{y}, \mathrm{s}, \mathrm{r}} \\
T_{\mathrm{x}, \mathrm{s}, \mathrm{r}} \\
T_{\mathrm{y}, \mathrm{s}, \mathrm{r}}
\end{array}\right]
\end{aligned}
$$

state, output and input vectors respectively, $Q$ and $R$ weighting matrices.

The deviations of the output vector, $\boldsymbol{y}$, and the control input, $\boldsymbol{u}$, from their reference values are penalized quadratically with nonnegative symmetric weighing matrices, $Q$, and $R$, 
correspondingly, in order to reflect different weights attached to different state and input components. With the choice of the weighing matrices, $Q$, and $R$, a trade-off between observer performance (increasing $Q$ ) and low input energy (increasing $R$ ) can be achieved. The $Q$ and $R$ parameters have been tuned in order to obtain satisfactory behavior of the observer.

For the observer design, the system model is represented in the state-space form:

$$
\begin{aligned}
& \dot{x}(t)=A x(t)+B u(t), \\
& y(t)=C x(t)+D u(t),
\end{aligned}
$$

where

$A, B, C, D$ - state-space matrices defined from the model.

This observer scheme allows to handle MIMO system problems almost as easily as SISO system problems.

An optimal trajectory is generated by choosing the input for $t \geq 0$ as:

$$
u(t)=-F_{\mathrm{c}} x(t), F_{\mathrm{c}}=R^{-1} B^{\mathrm{T}} X,
$$

where

$F_{\mathrm{c}}$ - state feedback gain matrix, $X$ - the symmetric matrix - the nonnegative-definite solution of the algebraic Riccati matrix equation (ARE):

$$
A^{\mathrm{T}} X+X A+C^{\mathrm{T}} B C-X B R^{-1} B^{\mathrm{T}} X=0 .
$$

This solution requires that the state $x(t)$ should be fully accessible for measurement. However, the states corresponding to linear and angular speeds and positions are not directly accessible and only the accelerations are measured. Thus, the reconstruction of the state $\dot{x}(t), \dot{\theta}(t)$ and $x(t)$ and $\theta(t)$ is performed using a single or double integrator respectively of the first harmonic of the corresponding acceleration, obtained from the Fast Fourier Transform (FFT) algorithm. This method also allows to avoid accumulation of the integration error. The resulted estimated force is presented in Figs. 9 - 14 together with the experimental measurements. The corresponding displacements are found using results of FEM solutions.

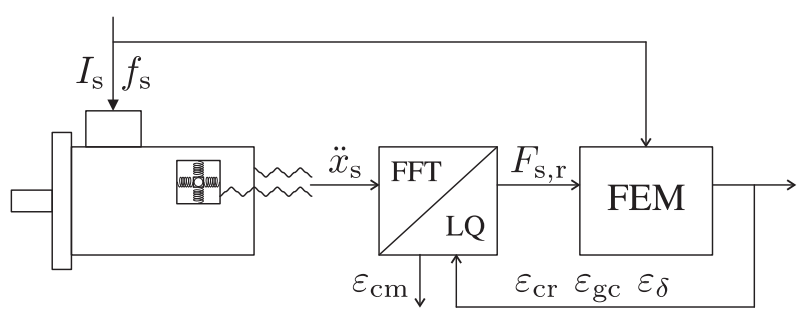

Figure 8. LQ and FEM observer scheme.

\section{CONCLUSION}

This paper describes a practical method of identification of sources and characteristics of unbalanced magnetic pull of induction motors. The main goal of this identification method is the improvement in the effectiveness and accuracy of motor diagnostic during production or testing phase. The proposed method is based on the detailed electromagnetic analysis of the motor together with a mathematical model of the mechanical structure.

The time-optimal MIMO LQ observer has been proposed for the identification of the parameters of the electromagnetically and mechanically unbalanced systems. It provides the movement of the operating point along the time-optimal trajectories, thus providing the identification in real time. As it was demonstrated, the proposed method provides effective identification of airgap and/or rotor eccentricity, using simplified mathematical models. The described method is regarded as the key component of the more global iterative analysis of the motor vibrations, with the identification of the motor parameters [14]-[16] included.

\section{REFERENCES}

[1] I. Shubov, Noise and vibration of electrical machines. Energoatomizdat, Leningrad, 1986.

[2] F. Gieras, L. J. Cho, and C. Wang, Noise of polyphase electric motors. CRC Press, Taylor \& Francis Group, 2006.

[3] P. Timar, Noise and Vibration of Electrical Machines. Elsevier Science Ltd, 1989.

[4] R. Belmans, D. Verdyck, W. Geysen, and R. Findlay, "Electromechanical analysis of the audible noise of an inverter-fed squirrel-cage induction motor," IEEE Trans. Ind. Appl., vol. 27, no. 3, pp. 539-544, May/Jun. 1991.

[5] R. Belmans, L. Hondt, A. Vandenput, and W. Geysen, "Analysis of the audible noise of three phase squirrel cage induction motors supplied by inverters," IEEE Trans. Ind. Appl., vol. IA-23, pp. 842-847, Sep./Oct. 1987.

[6] W. Finley, M. Hodowanec, and W. Holter, "An analytical approach to solving motor vibration problems," IEEE Trans. Ind. Appl., vol. 36, pp. 1467-1480, 2000.

[7] U. Werner, "Mathematical analysis of rotor shaft displacements in asynchronous machines; a critical speed or just a rotation of the orbit axis?" Zeitschrift fur angewandte Mathematik und Mechanik, vol. 89, no. 7, pp. 514-535, 2009.

[8] R. C. Hibbeler, Engineering Mechanics Static and Dynamics. Macmillan Publishing Company, New York, 1986.

[9] D. A. Wells, Theory and Problems of Lagrangian Dynamics. McGrawHill, Inc., 1967.

[10] D. T. Greenwood, Principles of Dynamics (2nd Edition). Prentice Hall, 1987.

[11] M. L. Adams, Rotating Machinery Vibration: From Analysis to Troubleshooting. Machinery Vibration Inc., Cleveland, Ohio, USA, 2000.

[12] J. L. Crassidis and J. L. Junkins, Optimal estimation of dynamic systems. Chapman \& Hall/CRC, 2004.

[13] E. Bryson, Dynamic Optimization. Addison Wesley Longman, Inc, 1999.

[14] K. Boynov, "Efficiency and time-optimal control of fuel cell - compressor - electrical drive systems," Ph.D. dissertation, Technische Universiteit Eindhoven, Eindhoven, The Netherlands, Aug. 2008

[15] I. Boldea and S. Nasar, The Induction Machine Handbook. CRC Press, Boca Raton, London, New York, Washington, D.C., 2000.

[16] E. Levi, Polyphase Motors: A Direct Approach to Their Design. John Wiley \& Sons Inc, 2000. 


\section{$F_{\mathrm{Y}}(.),.[\mathrm{kN}]$ and $a_{\mathrm{Y} 1}(--), a_{\mathrm{Y} 2}(-),\left[\mathrm{m} / \mathrm{s}^{2}\right]$}

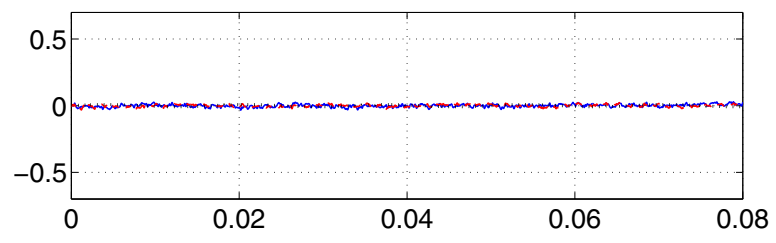

$F_{\mathrm{X}}(),.[\mathrm{kN}]$ and $a_{\mathrm{X} 1}(--), a_{\mathrm{X} 2}(-),\left[\mathrm{m} / \mathrm{s}^{2}\right]$

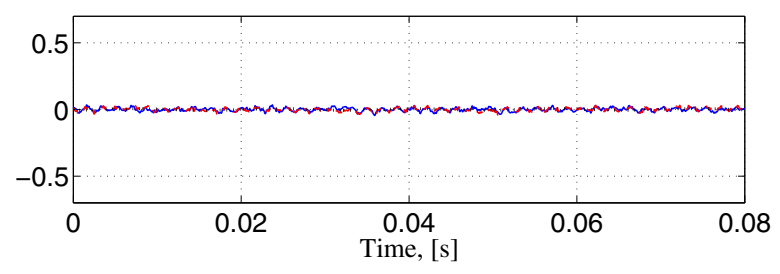

Figure 9. Zero displacement.

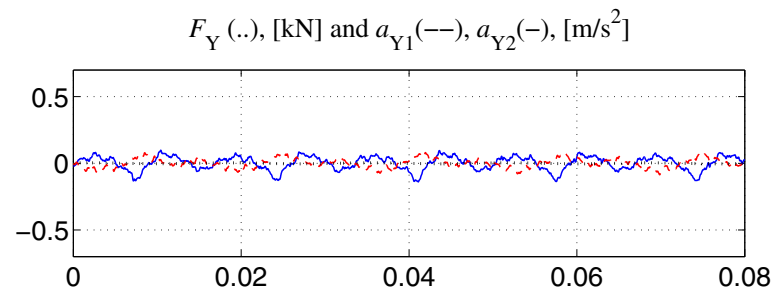

$F_{\mathrm{X}}(),.[\mathrm{kN}]$ and $a_{\mathrm{X} 1}(--), a_{\mathrm{X} 2}(-),\left[\mathrm{m} / \mathrm{s}^{2}\right]$

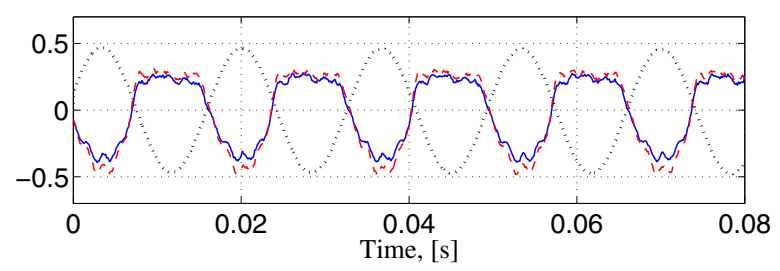

Figure 10. Displacement along $\mathrm{X}$-axis.

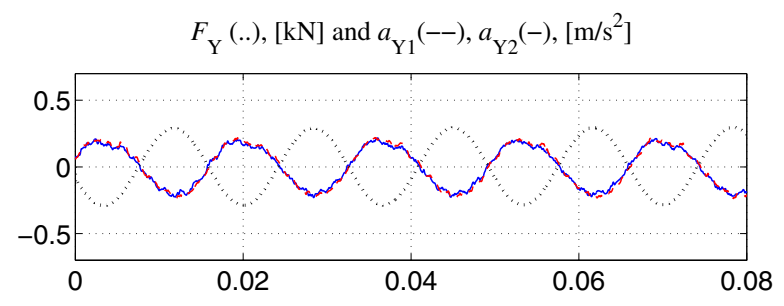

$F_{\mathrm{X}}(),.[\mathrm{kN}]$ and $a_{\mathrm{X} 1}(--), a_{\mathrm{X} 2}(-),\left[\mathrm{m} / \mathrm{s}^{2}\right]$

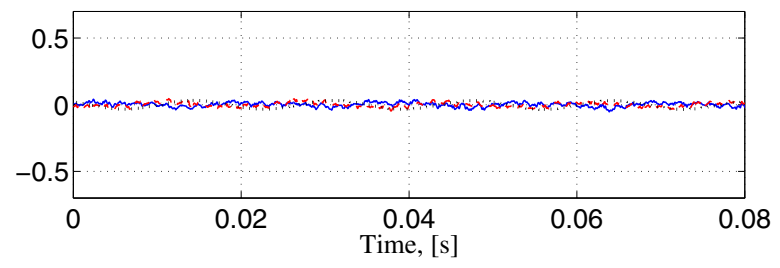

Figure 11. Displacement along Y-axis.
$F_{\mathrm{Y}}(.),.[\mathrm{kN}]$ and $a_{\mathrm{Y} 1}(--), a_{\mathrm{Y} 2}(-),\left[\mathrm{m} / \mathrm{s}^{2}\right]$

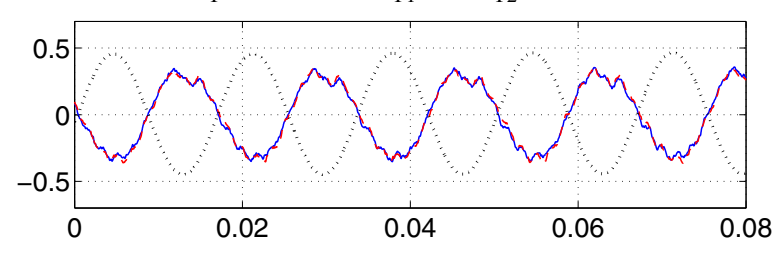

$F_{\mathrm{X}}(.),.[\mathrm{kN}]$ and $a_{\mathrm{X} 1}(--), a_{\mathrm{X} 2}(-),\left[\mathrm{m} / \mathrm{s}^{2}\right]$

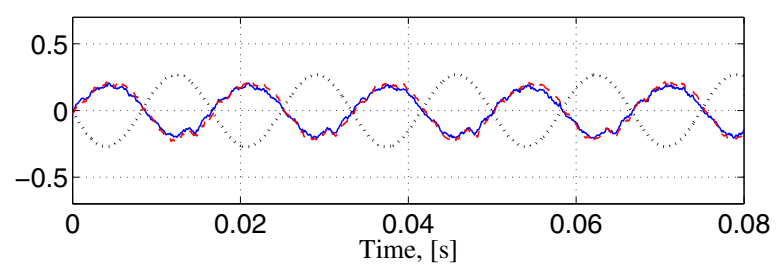

Figure 12. Displacement along X-and Y-axis.

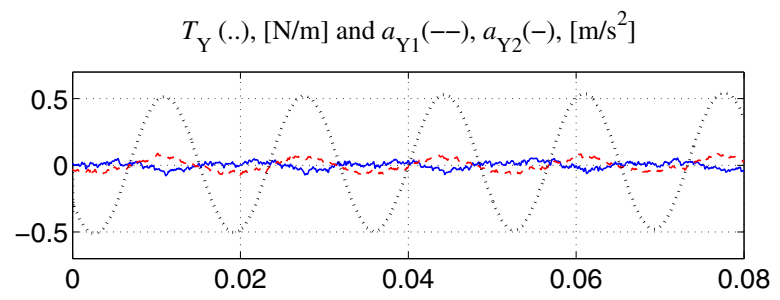

$F_{\mathrm{X}}(.),.[\mathrm{kN}]$ and $a_{\mathrm{X} 1}(--), a_{\mathrm{X} 2}(-),\left[\mathrm{m} / \mathrm{s}^{2}\right]$

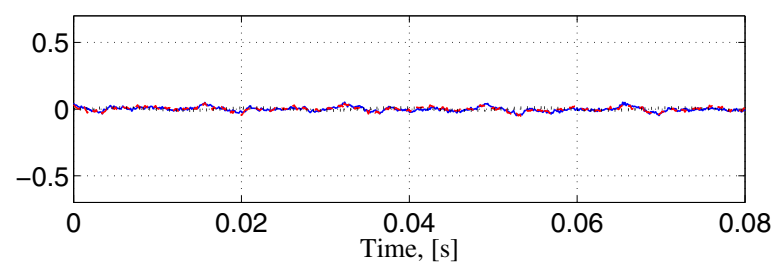

Figure 13. Angular displacement around Y-axis.

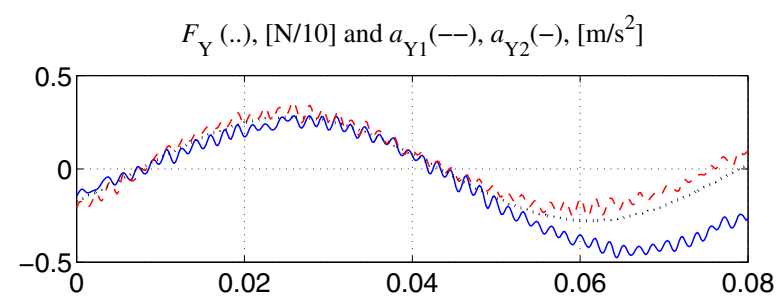

$F_{\mathrm{X}}(),.[\mathrm{N} / 10]$ and $a_{\mathrm{X} 1}(--), a_{\mathrm{X} 2}(-),\left[\mathrm{m} / \mathrm{s}^{2}\right]$

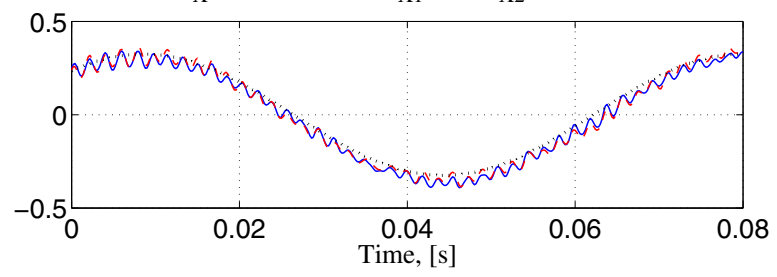

Figure 14. Displacement of the rotor center of mass. 